\title{
Influence of Additives of Nanoparticles on Structure Formation of Fine Grained Hardmetals
}

\author{
Yuri I.Gordeev ${ }^{1, a}$, Arthur K.Abkaryan ${ }^{1, b}$, Aleksandr S.Binchurov ${ }^{1, c}$,
}

Anatoli A. Lepeshev ${ }^{2, a}$,Vitaly B.Yasinski ${ }^{1, d}$

${ }^{1}$ Polytechnic Institute, Siberian Federal University, Kirensky str 26, Krasnoyarsk, 660074 Russia

${ }^{2}$ Krasnoyarsk Scientific Center, Siberian Branch, Russian Academy of Sciences, 50/50, Akademgorodok, Krasnoyarsk, 660074, Russia

atms-mtf@rambler.ru, ${ }^{\mathrm{b}}$ abkaryan_artur@mail.ru, ${ }^{\mathrm{c}} \underline{\text { mexanixs@mail.ru, }}{ }^{\mathrm{d}}$ VYasinskiy@sfu-kras.ru.

Keywords: hardmetal composites, nanoparticles, nanostructured materials, microstructure parameters, modelling and prediction of the properties, strength and fracture toughness.

Abstract. This paper introduces the new concept of coated fine carbides and modified by nanoparticles $\mathrm{Al}_{2} \mathrm{O}_{3}, \mathrm{ZrO}_{2}$ (inhibitors) as starting method for improved hardmetals. By calculated and experimental methods functional relationships between parameters of microstructure, sizes, volume content of additives of nanoparticles and properties (transverse rupture toughness, hardness, fracture toughness) of the heterophase hardmetal composites have been determined. Factors having a positive influence on the structure of hardmetals, are the decrease in the average size and contiguity of carbide grains due to SPS-consolidation and ultrasonic activation during mixing. The study of microstructural parameters by scanning electron microscopy in combination with x-ray phase analysis indicates a high statistical homogeneity of the relative distribution of nanoparticles (inhibitors) in the cobalt binder between carbide grains and the formation of nanostructured inclusions in hard metal composites.

\section{Introduction}

The analysis of the accumulated information on research and development of new compositions and manufacturing technologies of hardmetal composites and applications of carbide composites of various functionalities emphasize the use of components of powder materials with composite structure in the nanocrystalline state. The acknowledged world trend for improving the structure and properties of hardmetal composites is the use of nanostructured materials, formation of a more than fine-grained structure with grains of solid carbide phase with a size less than 300-400 nm. Application of nano and sub microcrystalline carbides and alloying additives of nanoparticles as grain growth inhibitors for the carbide phases are considered as the most prospective direction for production of nanostructured hardmetals with high hardness, strength and fracture toughness, which should extend the tool life of the product in conditions of heavy shock, and thermo-mechanical loads[1,2]. Problems of quality improvement of hard-metal alloys can be effectively solved due to their nanostructuring by use of tungsten carbide nanosized powders [3]. However, special unique characteristics of nanomaterials in most cases are formed and presented as isolated nanoparticles.

The retention of preferential differences of nanosized carbides in the process of consolidation and microvolume of hard-metal alloy is possible due to such methods as vacuum sintering [4], low temperature and rapid sintering, microwave processing [5, 6], hot isostatic pressing (HIP) [7] and spark plasma sintering (SPS) $[8,9]$. Moreover, the grain growth during sintering can be effectively inhibited. [10-12]. Coating of carbide particles by a binding layer is also a starting method which allows to obtain volumetric work pieces with the retention of unique properties of the initial nanopowders.

\section{Theory/calculation}

Previously developed geometric models and methods of calculating strength depending on the size, concentration and volume fractions of all components of WC-Co- $\mathrm{Al}_{2} \mathrm{O}_{3}\left(\mathrm{ZrO}_{2}\right)$, were used to assess the effectiveness of introduction of nanoparticles of $\mathrm{Al}_{2} \mathrm{O}_{3}$ into the structure of the cobalt binder and prediction of the final material properties at the stage of «design» [33]. In this case proceeding from the assumption that nanoparticles between the carbide grains in the binder phase, increase the strength on a fragmentary level and decrease the average thickness of the binder layer and inhibit 
the growth of the carbide grains and, as a result, increase the strength of the carbide composite as a whole. Based on these previously obtained experimental data, the geometric model has been refined. The research includes a new stereological approach to modeling. The offered stereological model consists of four matrix particles (WC) of the same size touching each other. The centers of spheres are the vertices of a tetrahedron whose edges are formed by radii $R_{i}$ (Fig. 1).

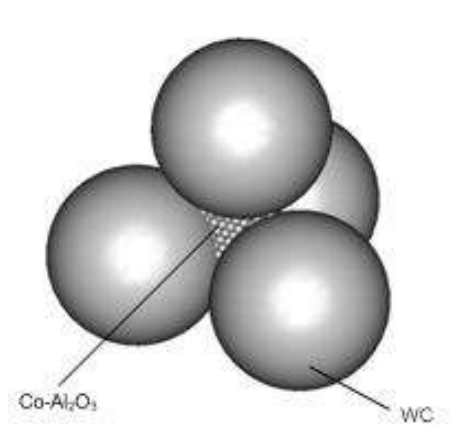

a)

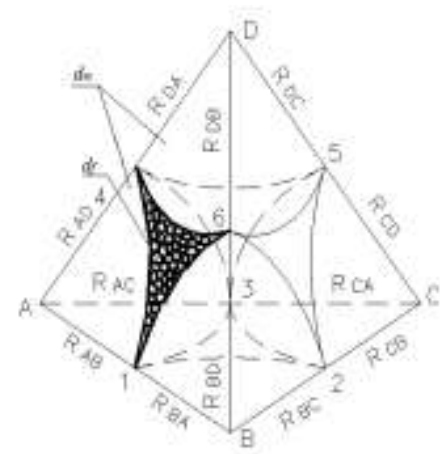

b)

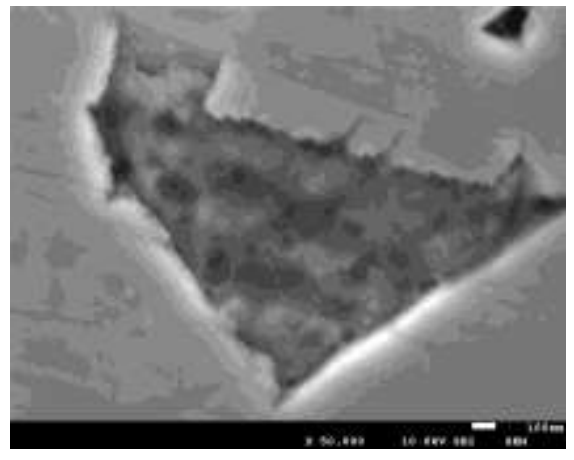

c)

Fig. 1. Stereological model of hard metal composites $\mathrm{WC}-\mathrm{Co}-\mathrm{Al}_{2} \mathrm{O}_{3}\left(\mathrm{ZrO}_{2}\right)$

(a) - the scheme of carbide particles packing $\left(\mathrm{d}_{\mathrm{m}}\right)$; (b) - a geometric model of the bimodal system $\mathrm{d}_{\mathrm{m}}(\mathrm{WC})$ - ceramic nano-additive $\mathrm{df}\left(\mathrm{Al}_{2} \mathrm{O}_{3 \mathrm{f}}, \mathrm{ZrO}_{2 \mathrm{f}}\right)$; (c) the real microstructure of the object.

Unit volume $\left(V_{c}\right)$ fragment of such structures with a bimodal particle size distribution $\left(d_{m}, d_{f}\right)$ can be determined from the ratio: $V_{c}=N_{m} v_{m}+v_{p}$, where: $N_{m}$ - denotes the quantity of carbide particles; $v_{m}$ the average volume of carbide particles. The void volume $\left(v_{p}\right)$ between the carbide particles based on the known rules of stereology and may be taken as $v_{b}=v_{p f}=0.20776\left(d_{f} / 2\right)^{3}$. As a means of increasing the density compacts need an additional amount of nano-phase $v_{f}$, equal to the volume of voids, $v_{p}=N_{f} v_{f}$. This condition is virtually impossible because the dense packing of the secondary nanoparticles forms its own voids $v_{p f}$ (Fig. 1b), i.e. $N_{f}$ must be reduced to $N_{f} *$. To eliminate residual porosity, the condition $v_{p f}=v_{b}$, must be satisfied where $\mathrm{v}_{\mathrm{b}}$ is the volume of binder metal $\left(N_{f}^{*}\right.$ particles can be calculated by analogy based on the above relation). With this approach to the problem of modeling the maximum density of the composite will be ensured. This is advantageous also on the basis of physical considerations, since the activation of sintering processes can be realized from layers of nanoparticles. The condition for the formation of a monolayer during sintering of nanoparticles and at the same time obtaining a dense composite structure requires a «cross-linking» of different models and leads to the following relations:

$$
\begin{aligned}
& \beta_{0} \cdot \sum_{i=1}^{N m}\left(d_{m}+d_{f}\right)^{3}=N_{m} \cdot v_{m}+N_{m} \cdot v_{\rho}-N_{f} \cdot v_{f} \\
& v_{h}=4 \pi\left(\left(R_{m}+h\right)^{3}-R_{m}{ }^{3}\right) / 3 R_{m}{ }^{3}
\end{aligned}
$$

where: $\beta_{0}$ - is the coefficient that determines the shape of the structure; $h$ - thickness of the layer of binder with nanoparticles $-\mathrm{d}_{\mathrm{f}}$, and $v_{\mathrm{h}}$ - is the layer volume.

Numerical values of composite particle parameters and thickness of a coating layer from metal binder on carbide composite powders can be also determined basing on a simple ratio: $\mathrm{Vh} / \mathrm{Vcm}=$ $6 \mathrm{~h} / \mathrm{dm}$, where: Vcm - volume of composite particle.

Solving this system of equations and using equations of the geometric model developed earlier [10, 12] for WC-Co-nano $\mathrm{Al}_{2} \mathrm{O}_{3}\left(\mathrm{ZrO}_{2}\right)$ the optimum volume of modifying additives at different ratios of average sizes $d_{m} / d_{f}$ and volume of particles $v_{m} / v_{f}$ can be determined In accordance with the geometric model calculation a prediction about the amount of additives needed to obtain compacts with the highest packing density is possible. Estimates were made in the carbide phase size in the range of $d_{m}$ (WC) from 0.5 to $3 \mu \mathrm{m}$ and for ultrafine particle sizes of 0,008 to $0.1 \mu \mathrm{m}$. In particular, when the particle size $d_{m}=3 \mu \mathrm{m} ; d_{f}=80 \mathrm{~nm}$, and the required concentration of additives in the mixture has been determined as $V_{f}=0,30 \%$ or about 3 wt. $\%$. 


\section{Experimental Results and Discussion}

Nanopowders obtained by shock-wave synthesis or by electric explosion were used as strengthening additives for hard metals. The average particle sizes ranged from $0,067 \div 0.1 \mu \mathrm{m}$ for $\mathrm{Al}_{2} \mathrm{O}_{3}(\delta, \alpha)-0.008 \mu \mathrm{m}$ for $\mathrm{ZrO}_{2}\left(\mathrm{Y}_{2} \mathrm{O}_{3}\right)$ and $0.2-0.4 \mu \mathrm{m}$ for composite powders (WC-Co). The electron microscope study indicates that the real microstructural parameters differ from the model ones. The presence of such fragments is illustrated by the results of the microstructural study - fig. 2. In the case of low concentrations, the nanoparticles are dispersed in the binder (Fig. 2,a, b). Local changes of the quantity of nanoparticle additives in separate unit volumes, fragments show the differences in parameters of composite microstructure. If to increase the contacting ability of nanoparticles in local volume, the formation of agglomerates shall take place due to insufficient uniformity of mixing of the components. During the process of sintering of heterogeneous hardmetal composites, the interfacial energy changes, due to a decrease in specific surface area of nanodispersed phases, followed by their coagulation. In case of random filling of voids between carbide grains, the different fragments may be formed by oxide particles which have different grade of in-touch capability and internal microporosity: single isolated inclusions of the nanoparticles (Fig. 2b), non-hard sinters from nanoparticles (Fig. 2c), This can be reasonably understood based on physical grounds and well-known principles of the theory of sintering of multiphase mediums.

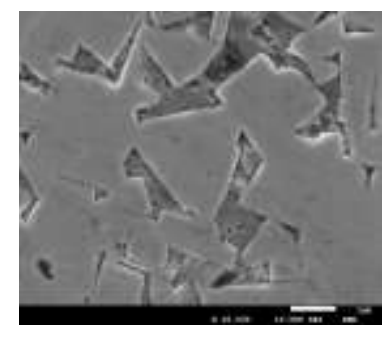

(a)

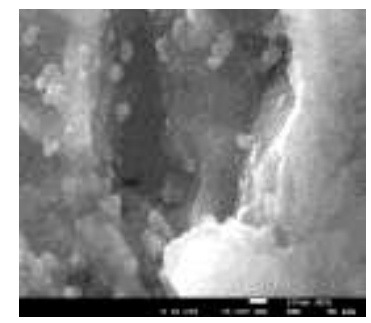

(b)

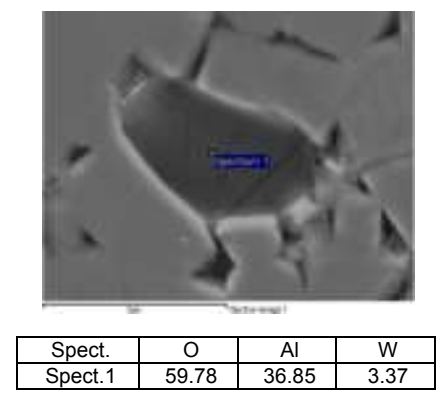

(c)

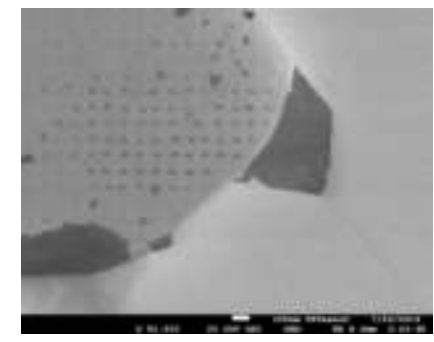

(d)

Fig. 2. Distribution of nanoparticles between carbide grains (a) microstructure WC-Co-nano $\mathrm{Al}_{2} \mathrm{O}_{3}$; (b) fracture fragment (inclusions of nanoparticles are visible between the carbide grains).

(c,d) quasi-nanocrystalline inclusions $\mathrm{Al}_{2} \mathrm{O}_{3}$

Moreover, when some critical concentration of the nanoparticles is reached and the pressure is originated between dispersed carbide phases during the liquid phase sintering, there can be a spontaneous formation of volumetric 3D-structural network. Apparently, main elements of the network are contacts between nanoparticles and the nanoparticles themselves, which collectively form 3D-cells (Fig.2d). Agglomerates, originating from ceramics nanoparticles, become nanostructured, i.e. they transit into an absolutely new state. Origination of such quasinanocrystalline fragments and transitions from freely-dispersed to ordered-dispersed (aggregated) systems principally change their basic mechanical properties. This research work provides a method for pre-treatment to ensure uniform distribution of nanoparticles - grain growth inhibitor in the volume of the cobalt binder and the formation of nanostructured inclusions in the hard metal composite. Taken together, the results calculated (by model) and experimental studies (by scanning electron microscopy in combination with the use of element analysis) allow to implement the required (predicted) parameters of the microstructure with a sufficiently high uniformity of distribution of phase components (tungsten carbide grain, metallic binder layer and modifiers nanoparticles) in the volume of hardmetal composite (Fig. 3).

Furthermore, fine carbides require special methods of consolidation and sintering. The study of special seals WC-Co alloy with the original dimensions of the carbide grains about $0,8 \mu \mathrm{m}$ show that intensive shrinkage occurs in the temperature range of $1320-1350^{\circ} \mathrm{C}$. These data are in good agreement with the results given in [1,2]. In the temperature range from $1370{ }^{\circ} \mathrm{C}-1420{ }^{\circ} \mathrm{C}$ to recrystallize the grain size to $1,5 \mu \mathrm{m}$ WC phase, even in the presence of grain growth inhibitors (modifying nanoparticles $\mathrm{Al}_{2} \mathrm{O}_{3}, \mathrm{ZrO}_{2}$ ). Additional studies show that the quality control of sintered hard metals can be achieved by alternative methods of consolidation and step by step heating 
(«reference» point corresponds to the change in the mechanism of consolidation), thermomechanical treatments and compressive sintering [29, 38, 39].

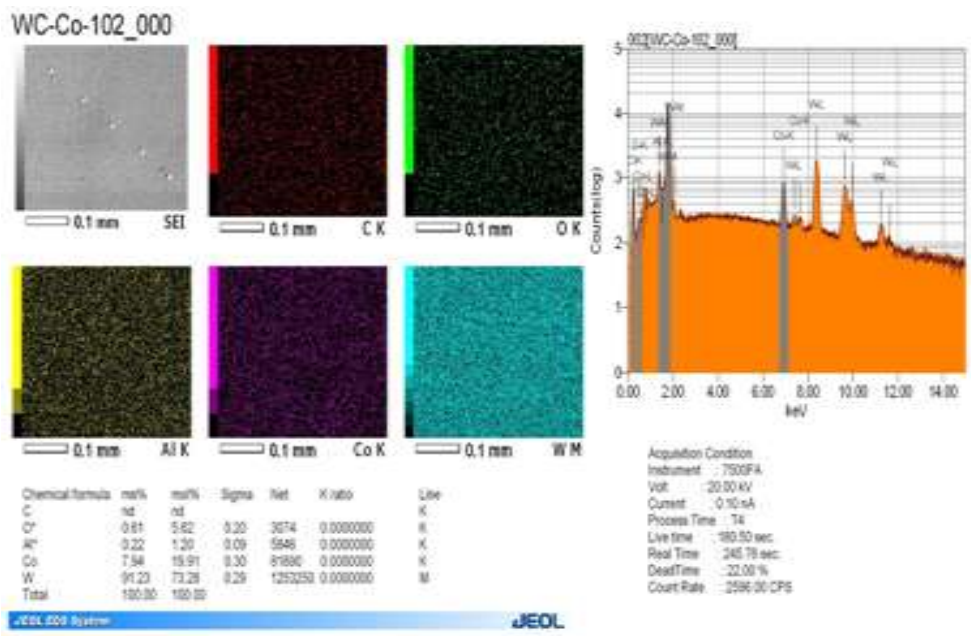

Fig. 3. Distribution of phase components in WC-Co- $\mathrm{Al}_{2} \mathrm{O}_{3}$ hard metal: electron microscopic images of hard metal composite and EDS-map of local deposition components.

The physical meaning of such an exposure is a kind of «swing» of the material, the activation process of structure formation. Ultimately, this will reduce the sintering temperature and form a fine-grained structure of the hard metal composite alloyed with $\mathrm{Al}_{2} \mathrm{O}_{3}, \mathrm{ZrO}_{2}$. The results of X-ray phase analysis of the consolidated specimens revealed that the hard-metal composite, produced by SPS method, alloyed by the nanoparticles of zirconium dioxide in amount of $1 \%$, has the average crystal grains size (coherent scattering region) of tungsten carbide as $244 \mathrm{~nm}$. The increase of the content of alloying additive up to $3 \%$ causes significant restraint of the growth process of the WC grain size: the average size of coherent scattering region for these specimens was in the range of 151 to $163 \mathrm{~nm}$. The average size of coherent scattering region of the cobalt binder is not more than $22 \mathrm{~nm}$, according to the data of X-ray phase analysis. [8,9]. Nano-additives changed the parameters of the microstructure (the average carbide grain size, the average binder layer thickness, the length of the carbide boundaries et al.), reinforced binder layer and increase the physical, mechanical and performance properties of hard metals composite as a whole. New approach for the improvement of hardmetal composites quality involves using of composite nanopowders (WC-Co) Fig. 4, obtained by the methods of chemical deposition together with microwave effect [ 13].

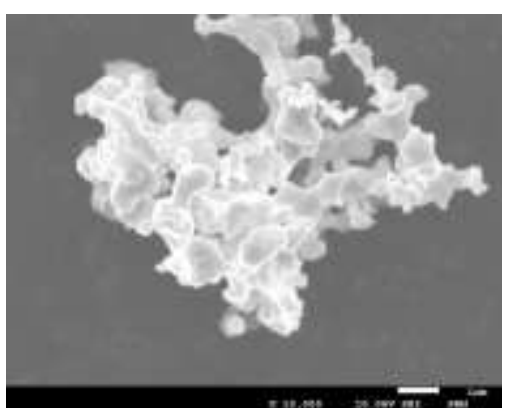

a)

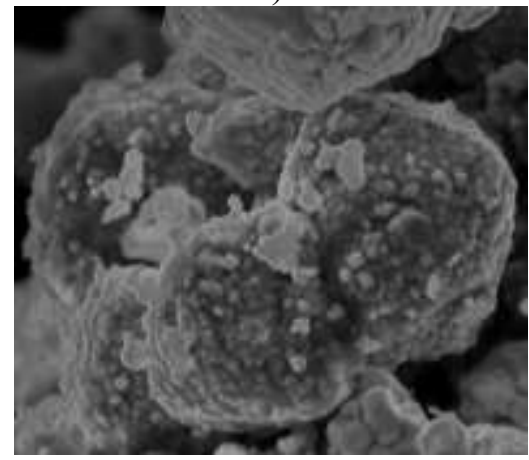

b)

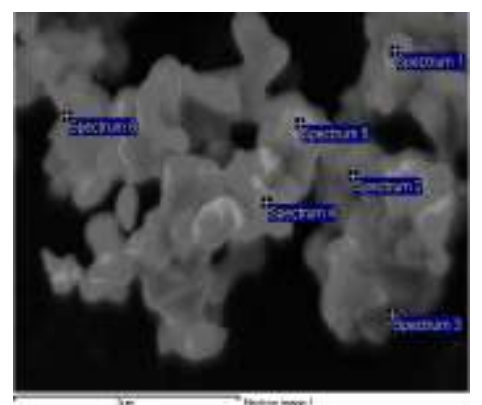

c)

\begin{tabular}{|l|c|c|c|c|}
\hline Spectrum & C & O & Co & W \\
\hline Spectrum 1 & 76.22 & 3.35 & 2.09 & 18.34 \\
\hline Spectrum 2 & 61.08 & 3.93 & 7.11 & 27.88 \\
\hline Spectrum 3 & 86.56 & 1.48 & 1.35 & 10.61 \\
\hline Spectrum 4 & 73.87 & 3.36 & 1.61 & 21.16 \\
\hline Spectrum 5 & 73.22 & 2.61 & 1.83 & 22.35 \\
\hline Spectrum 6 & 80.20 & 3.71 & 3.19 & 12.91 \\
\hline
\end{tabular}

Fig. 4 - Morfology of composite powders WC-Co a, c) microvave effect powders; $b$ ) - produced by chemical coating; c)-EDS of composite powders 
The structure, formed by simple sintering of a hard metal consists of almost isolated carbide grains partially overlapped due to elastic cobalt shell - Fig. 5a. The specific of the described approach is the account of differences in compaction kinetics and mass-transfer in particles of micron and submicron component with the use of developed stereological models - Fig 5c, Fig 1. It is also necessary to count that intercarbide space is filled with cobalt from the coating layer of composite powders (Co-WC) and oxide nanoparticle additives.

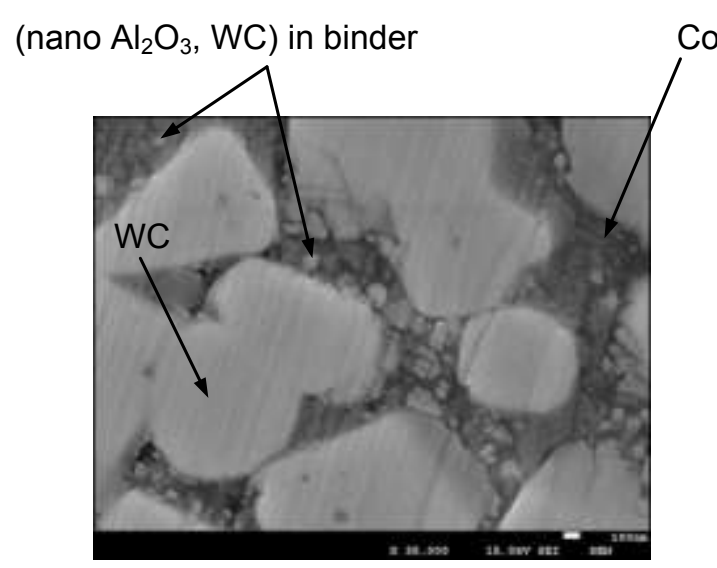

a)

Fig. 5 - Microstructure of hard metals formed from composite powders WC-Co (a) SEM (b) elements analyses EDS

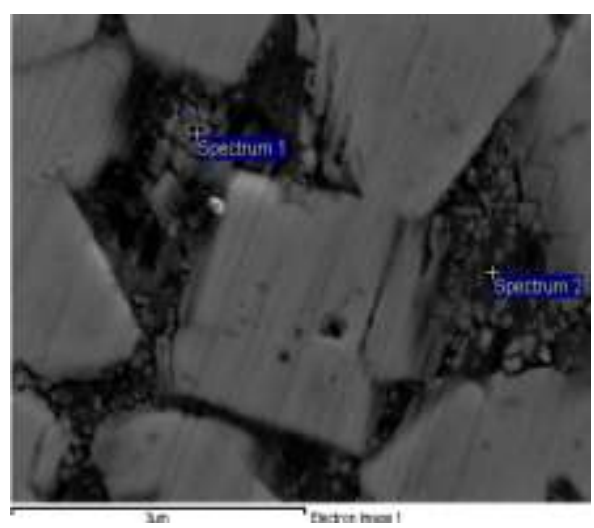

b)

\begin{tabular}{|l|c|c|c|c|c|}
\hline Spectrum & C & O & Co & Al & W \\
\hline Spectrum 1 & 24.94 & 10.44 & 8.44 & 1.44 & 54.74 \\
\hline Spectrum 2 & 16.89 & - & 2.56 & 2.20 & 78.35 \\
\hline
\end{tabular}

At microscopic level, the structural fragments which are statically uniformly distributed over the material's volume, collectively form new composite of a more complex level. Such multiphase composite is characterized by the additional heterogeneity, determined by the differences in elastic properties of phases. It appears through non-uniformity of stress-strain state during liquid phase sintering in the process of production (in interphase boundaries, in the process of shrinkage, compaction) as well as under external mechanical impact on compacted material. The crack, which is distributed mostly over the interphase boundaries $\mathrm{WC}-\mathrm{WC}, \mathrm{WC}-\mathrm{Co}$ is blocked and relaxes on dispersive inclusions of nanoparticles $\mathrm{Al}_{2} \mathrm{O}_{3}, \mathrm{ZrO}_{2}$ places in cobalt interlayer volume.

Parametric experimental studies (using advanced techniques, including x-ray analysis, electron microscopy, emission scanning electron microscopy, high-resolution method photographic correlation spectroscopy, optical profilometry, measurement of tensile strength, hardness, fracture toughness, wear resistance and etc.) allow us to establish the functional relationship between the properties of powders (submicron, nanocrystalline) parameters of microstructure and final properties of hard metals. (Table. 1).

Table 1 - The strength characteristics of samples of hardmetal composites

\begin{tabular}{|c|c|c|c|c|}
\hline \multirow{2}{*}{\multicolumn{2}{|c|}{ Samples of hardmetal }} & \multicolumn{3}{|c|}{ Physical-mechanical characteristics } \\
\hline & & $\begin{array}{l}\text { Hardness } \\
\mathrm{HV}, \mathrm{GPa}\end{array}$ & $\begin{array}{c}\text { Transverse } \\
\text { rupture strength } \\
\sigma_{\mathrm{b}}, \mathrm{GPa}\end{array}$ & $\begin{array}{l}\text { Fracture toughness } \\
\mathrm{K}_{1 \mathrm{c}} \mathrm{MPa} \cdot \mathrm{m}^{1 / 2}\end{array}$ \\
\hline \multicolumn{2}{|c|}{$\mathrm{WC}-15 \mathrm{Co}+\left(\mathrm{Al}_{2} \mathrm{O}_{3 \mathrm{f} \text { (nano) }}\right)$} & 12,7 & 2,54 & 21,6 \\
\hline \multicolumn{2}{|c|}{$\mathrm{WC}-10 \mathrm{Co}+\left(\mathrm{Al}_{2} \mathrm{O}_{3 \mathrm{f}(\text { (nano) }}\right)$} & 15,1 & 2,68 & 19,3 \\
\hline \multicolumn{2}{|c|}{$\mathrm{WC}-8 \mathrm{Co}+\left(\mathrm{Al}_{2} \mathrm{O}_{3 \mathrm{f}(\text { nano })}\right)$} & 15,5 & 2,75 & 18,0 \\
\hline \multirow{3}{*}{$\begin{array}{c}\text { nanocrystalline } \\
\text { hardmetal (SPS } \\
\text { synthesis) }\end{array}$} & $\mathrm{WC}-6 \mathrm{Co}$ & $19,5 \pm 0,6$ & $2,13 \pm 0,1$ & $9,1 \pm 0,6$ \\
\hline & $\mathrm{WC}-6 \mathrm{Co}+2 \% \mathrm{ZrO}_{2 \mathrm{f}}$ & $20,4 \pm 0,6$ & $2,7 \pm 0,1$ & $9,3 \pm 0,7$ \\
\hline & $\mathrm{WC}-6 \mathrm{Co}+3 \% \mathrm{ZrO}_{2 \mathrm{f}}$ & $22,0 \pm 0,6$ & $2,9 \pm 0,1$ & 9,7 \\
\hline
\end{tabular}


An extremely important finding, which was discovered and was repeated in the study of the microstructure of hardmetals modified by nanoparticles is a stable decrease in the average sizes of the carbide grains of the main phase WC.

Summarizing, the results of experimental studies in combination with the methods of computer modelling and prediction of hardmetal composites properties, that was modified with additives of ceramic nanoparticles and composite powders (WC-Co) provide improvement in controlling microstructure and level of physical - mechanical properties of hardmetal products.

\section{Acknowledgements}

The reported study was funded by RFBR according to the research project № 17-08-01443

\section{References}

[1] Fang Zak Z., Wang Xu, Taegong Ryu, Kyu Sup Hwang, Sohn H.Y. Synthesis, sintering, and mechanical properties of nanocrystalline cemented tungsten carbide - A review// Int. Journal of Refractory Metals \& Hard Materials. - 2009. - vol. 27, pp. 288-299

[2] Panov, V.S., Zaitsev AA Trends of development the technology ultrafine and nanosized tungsten carbide WC-Co- A review //Proceedings of the universities. Powder metallurgy and functional coatings, 2014, no. 3, pp. 38-48.

[3] Andrievski R., Glazer A. // Strength of nanostructures. UFN, 2009, 179: 4, p.337-358.

[4] C. Jia, L. Sun, H. Tang, X. Qu, Int. J. Refract. Metals Hard Mater. 25 (2007) 53-56.

[5] Bykov Yu.V.,Rybakov K.I., Semenov V.E. High-temperature microwave processing of materials // J. Appl. Phys. 2001. V. 34. № 13. P. R55-R75.

[6] K. Essaki, E.J. Rees, and G.T. Burstein. Synthesis of Nanoparticulate Tungsten Carbide Under Microwave Irradiation // J. Amer. Ceram. Sos. - 2010. - T. 93. - № 3. - C. 692-695.

[7] I. Azcona, A. Ordnez, J.M. Sanchez, F. Castro, J. Mater. Sci. 37 (2002) 4189-4195.

[8] S.I. Cha, S.H. Hong, B.K. Kim, Mater. Sci. Eng. A351 (2003) 31-38. [21] R. Chaim, Mater. Sci. Eng. A 443 (2007) 25-32.

[9] Khasanov O., Kachaev A., Dvilis E., Khasanov A. //11th International Conference and Exhibition of the European Ceramic Society. Krakow, 21-25 June 2009. Abstracts. 2009. p. 146.

[10] Gordeev Yu., Abkaryan A., Zeer G. Design and research of cemented carbides and ceramic composites modified by nanoparticles // Advanced Materials. 2012, no.5, p. 76-88.

[11] Huang, S.G. NbC as grain growth inhibitor and carbide in WC-Co hardmetals / S.G. Huang, R.L. Liu, L. Li [ect.] // International Journal of Refractory Metals \& Hard Materials. -2008. №26. -P. 389-395.

[12] Gordeev, Y. I., Abkaryan, A. K., Binchurov, A. S., \& Jasinski, V. B. Design and Investigation of Hard Metal Composites Modified by Nanoparticles //Advanced Materials Research. - 2014. vol. 1040, pp. 13-18.

[13] Nikolaenko, I., Kedin, N., \& Shveikin, G. (2014). Synthesis of ultrafine powder (W, Ti) C by microwave heating in a stream of argon. International Journal of Materials Research, 105(12), 1232-1235. 